\title{
Regulation of autophagy inhibition and inflammatory response in glioma by Wnt signaling pathway
}

\author{
TONGXIN WANG, ZHIXIA CHEN and WEI ZHANG \\ Department of Neurosurgery, Yidu Central Hospital of Weifang, Qingzhou, Shandong 262500, P.R. China
}

Received May 20, 2017; Accepted September 21, 2017

DOI: $10.3892 / \mathrm{ol} .2017 .7103$

\begin{abstract}
The objective of this study was to investigate the mechanism of the function of Wnt signaling pathway in regulating autophagy and inflammatory response in glioma cells. Human brain glioma cells U118 were selected and divided into three groups: i) the Wnt signaling inhibitor IWR-1 group (the observation group); ii) the PBS negative control group (the PBS group) and iii) the blank control group. After $24 \mathrm{~h}$ culture, Wnt $5 \mathrm{a} / \beta$-catenin protein, autophagy marker, microtubule-associated-proteins-1 A1B-light-chain-3C (LC-3) II and Beclin I, and inflammatory factors IL- 6 and TNF- $\alpha$ protein expression levels were evaluated using western blotting. Compared with both control groups, Wnt5a/ $\beta$-catenin, IL- 6 and TNF- $\alpha$ protein expression levels were significantly lower, and LC-3II and Beclin I protein expression levels were significantly higher in the observation group. In conclusion, Wnt5a/ $\beta$-catenin signaling pathway regulates autophagy and inflammatory response of glioma cells.
\end{abstract}

\section{Introduction}

Glioma, a major malignant tumor of the central nervous system, is characterized by high incidence, recurrence and mortality rates, and low cure rate (1). In-depth analysis of the mechanism of tumorigenesis and the identification of specific molecular markers and intervention targets has become a hot topic in tumor research. Several studies have confirmed that, Wnt signaling pathway, which is closely related to central nervous system diseases, is involved in the proliferation, migration and differentiation processes of neural stem cells (2). The classic Wnt/ $\beta$-catenin pathway has been extensively studied (2). Autophagy, also known as type II programmed cell death, has been proved to be closely related to the maintenance of cell homeostasis and occurrence of disease. Autophagy can

Correspondence to: Dr Tongxin Wang, Department of Neurosurgery, Yidu Central Hospital of Weifang, 4138 Linglongshannan Road, Qingzhou, Shandong 262500, P.R. China

E-mail: drtongxinwang@163.com

Key words: Wnt5a/ $\beta$-catenin signaling pathway, glioma cells, autophagy, inflammatory response participate in the cell cycle, cell proliferation, cell apoptosis and angiogenesis of tumor cells, thus affecting occurrence and development of tumors $(3,4)$. A variety of chemotherapy drugs can induce autophagic activity of glioma cells, which in turn show a curative effect, and reduce drug resistance (5). Inflammation is also an important factor involved in the development, progression and treatment processes of various tumor cells (6). Based on the above, the aim of this study was to analyze the mechanism of Wnt signaling pathway in the regulation of autophagy and inflammatory response in glioma cells.

\section{Materials and methods}

Experimental materials. Human glioma cell line U118 was purchased from Research Science (Shanghai, China); High glucose DMEM medium and fetal bovine serum were purchased from Sigma (St. Louis, MO, USA); Wnt inhibitor IWR-1 was from Beyotime (Jiangsu, China); RIPA lysate and phenylmethylsulfonyl fluoride (PMSF) were purchased from Beijing Zhongshan Golden Bridge Biotechnology Co., Ltd.; BCA kits were from Europe B.V. (Venlo, The Netherlands); mouse anti-human Wnt5a, $\beta$-catenin, marker microtubule-associated-proteins-1A/1B-light-chain-3C (LC-3) II and Beclin I, IL-6 and TNF- $\alpha$ monoclonal antibodies were from Santa Cruz Biotechnology, Inc. (Santa Cruz, CA, USA) (cat. nos. sc-365370, sc-65480, sc-398822, sc-48341, sc-130326 and sc-130349); $\beta$-actin antibody and rabbit anti-mouse polyclonal antibody were purchased from Invitrogen (Carlsbad, CA, USA) (cat. no. MA5-15739, A-11059); TBST and ECL solutions were purchased from General Electric Co. (Fairfield, CT, USA); Cell culture plates and $\mathrm{CO}_{2}$ incubators were from Bio-Rad (Hercules, CA, USA), electrophoresis apparatus trophoresis was from Applied Biosystems (City Foster, CA, USA); Polyvinylidene fluoride film (PDVF) was from R\&D Systems (Minneapolis, MN, USA).

Experimental grouping. After resuscitation, U118 cells were cultured with high glucose DMEM medium containing 10\% fetal bovine serum in an incubator $\left(37^{\circ} \mathrm{C}, 5 \% \mathrm{CO}_{2}\right)$. Subcultures were prepared and medium was replaced every other day. Cells were collected during the logarithmic growth phase and resuspended in PBS to adjust the density to $2 \times 10^{6} / \mathrm{ml}$. Cells were divided into 3 groups: the Wnt signal pathway inhibitor IWR-1 group ( $5 \mu \mathrm{mol} / 1$, observation group), the PBS negative 


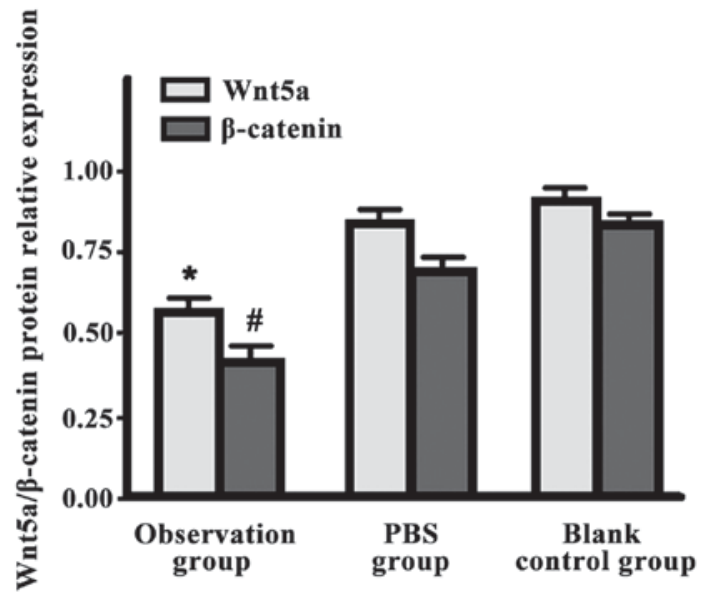

Figure 1. Expression levels of Wnt5a/ $\beta$-catenin protein in culture medium of each group detected by western blotting. "P<0.05, expression of Wnt5a protein in observation group was significantly lower than that in the other two groups; ${ }^{\prime} \mathrm{P}<0.05$, expression of $\beta$-catenin protein in observation group was significantly lower than that in the other two groups.



Figure 2. Expression levels of LC-3 II and Beclin I protein in culture medium of each group detected by western blotting. "P<0.05, expression of LC-3 II protein in observation group was significantly lower than that in the other two groups; ${ }^{\#} \mathrm{P}<0.05$, expression of Beclin I protein in observation group was significantly lower than that in the other two groups.

control group (PBS group) and the blank control group. All groups were incubated for another $24 \mathrm{~h}$.

Observation indicators and examination methods. Western blot was used to evaluate $\mathrm{Wnt} 5 \mathrm{a} / \beta$-catenin protein, autophagy marker microtubule-associated-proteins-1A1B-light-chain-3C (LC-3) II and Beclin I, and inflammatory factors IL-6 and TNF- $\alpha$ protein expression levels. Western blotting: medium containing cells of each group was placed on ice, and $150 \mu \mathrm{l}$ of RIPA lysate and $1.5 \mu \mathrm{l}$ of PMSF were added and incubated for $30 \mathrm{~min}$, followed by centrifugation $(2,000 \mathrm{x} \mathrm{g})$ at $4{ }^{\circ} \mathrm{C}$ for $20 \mathrm{~min}$ and the supernatant was collected. Protein concentration was measured using BCA method. Protein $(15 \mu \mathrm{g})$ from each sample was subjected to $8 \%$ polyacrylamide gel (SDS-PAGE) electrophoresis, followed by transfer to PDVF membrane. Membrane was blocked with 5\% skimmed milk at room temperature for $2 \mathrm{~h}$. Mouse anti-human Wnt5a,

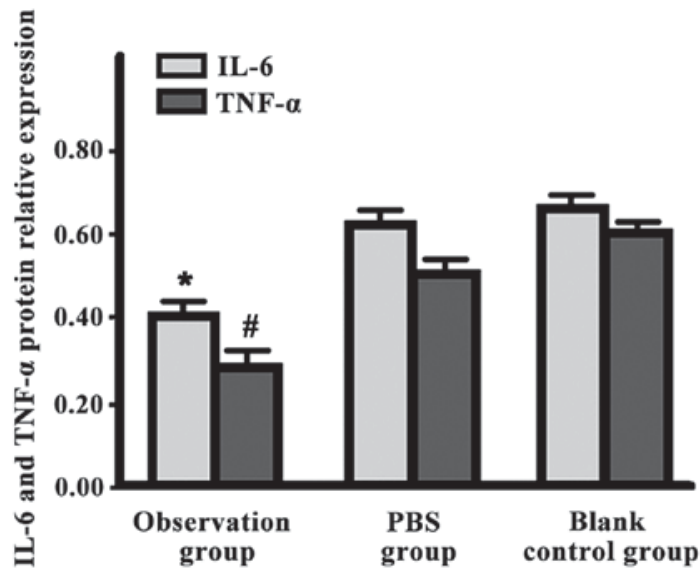

Figure 3. Expression levels of IL-6 and TNF- $\alpha$ protein in culture medium of each group detected by western blotting. ${ }^{*} \mathrm{P}<0.05$, expression of IL- 6 protein in observation group was significantly lower than that in the other two groups; ${ }^{\#} \mathrm{P}<0.05$, expression of $\mathrm{TNF}-\alpha$ protein in observation group was significantly lower than that in the other two groups.

$\beta$-catenin, LC-3 II, Beclin I, IL-6 and TNF- $\alpha$ monoclonal antibodies $(1: 2,000)$ were then added and incubated overnight at $4^{\circ} \mathrm{C}$. After washing with TBST, rabbit anti-mouse polyclonal antibody (1:500) was added and incubated at room temperature for $4 \mathrm{~h}$. After washing with TBST, color development with ECL was performed, and results were scanned and recorded. Lab Works 4.5 gel imaging software (Invitrogen) was used for semi-quantitative analysis with results expressed as integrated optical density (IOD). The relative expression levels of targeted proteins were represented by the ratio of IOD to that of $\beta$-actin (endogenous control).

Statistical analysis. Statistical analysis was performed using SPSS 20.0 software (SPSS Inc., Chicago, IL, USA). Measurement data were expressed as mean \pm standard deviation. Single factor ANOVA analysis was used for comparisons among multiple groups and LSD-t method was used for the comparisons between 2 groups. $\mathrm{P}<0.05$ was considered to indicate a statistically significant difference.

\section{Results}

Expression levels of Wnt5a/ $\beta$-catenin protein. Wnt5a/ $\beta$ catenin protein expression levels in the observation group were significantly lower than those in the other two groups $(\mathrm{P}<0.05)$ (Fig. 1).

Expression levels of LC-3 II and Beclin I. LC-3 II and Beclin I expression levels in the observation group were significantly higher than those in the other two groups $(\mathrm{P}<0.05)$ (Fig. 2).

Expression levels of IL- 6 and TNF- $\alpha$. IL-6 and TNF- $\alpha$ expression levels in the observation group were significantly lower than those in the other two groups $(\mathrm{P}<0.05)$ (Fig. 3).

\section{Discussion}

Wnt pathway includes classical Wnt/ $\beta$-catenin, Wnt/PCP (7) and $\mathrm{Wnt} / \mathrm{Ca}^{2+}$ pathway (8), within which the activation of 
Wnt/ $\beta$-catenin can lead to the binding of Wnt protein to specific cell surface frizzled receptor proteins and low density lipoprotein receptor-related protein 5/6 (9). This binding can activate the intracellular PDZ domain containing dishevelled protein and Axin protein to inhibit the phosphorylation of glycogen synthase kinase 3 (GSK 3), and consequently lead to the accumulation of $\beta$-catenin in cytoplasm (9). $\beta$-catenin can enter nucleus and bind to the transcription factor $\mathrm{T}$ cytokine/ lymphotropic enhancer family protein and initiate the transcription, thereby regulating the expression of downstream related target genes and promoting proliferation, invasion and metastasis of tumor cells (10). Our results showed that Wnt $5 \mathrm{a} / \beta$-catenin, IL-6 and TNF- $\alpha$ protein expression levels were significantly lower and LC-3II and Beclin I protein expression levels were significantly higher in observation group. Therefore, we believe that $\mathrm{Wnt} 5 \mathrm{a} / \beta$-catenin signaling pathway regulates the autophagy and inflammatory response of glioma cells.

Prior studies confirmed (11) that Wnt is a key factor in the self-renewal of neural stem cells, and Wnt also participates in neural formation in adult brain tissue. Mutations of Wnt gene and knockout of Wntl gene can lead to the loss of midbrain in mice (12). Wnt can act on mouse neural precursor cells to increase the number of new neurons (13). Wnt pathway can also affect the synaptic transmission and plasticity of hippocampal neurons (14). Wnt/ $\beta$-catenin pathway in adult brain is closely related to the occurrence of Alzheimer's disease (15). Wnt5a protein is a member of the Wnt protein family, which can mediate nonclassical pathways to inhibit classical pathways, and the inhibition of classic pathwaty can in turn trigger Wnt5a pathway to participate in regulating the development of the central nervous system (16). IWR-1 is a small molecule inhibitor of the Wnt pathway that plays a role in stabilizing Axin degradation complex (17). LC3 is a marker protein used for detecting autophagy. LC3-I has the ability to bind to phosphatidylethanolamine after autophagy and form LC3-II. LC3-II is localized in the phagocytic endometrium and adventitia and can be kept stably in autophagic membrane until the fusion with lysosomes (18). LC3-II level can reflect the number of autophagosomes and the degree of autophagy (18). Beclin I is the first identified mammalian autophagy protein, and it has been shown that Beclin I gene deletion is directly related to the development of human breast cancer (19), colorectal cancer (20) and prostate cancer (21). The recovery of Beclin I expression can induce autophagy and inhibit the occurrence and development of tumors. Mechanism of autophagy in treatment response of cancer is complex. Autophagy can both suppress and protect tumor cells (22) and there are researchers who believe that the regulation of autophagy may be a new target for the treatment of a variety of tumors.

In addition, inflammatory response with IL- 6 and TNF- $\alpha$ as the central network factors, is also an important mechanism involved in tumorigenesis. It has been confirmed that, the occurrence, development, treatment and prognosis of lung cancer (23), liver cancer (24), colorectal cancer (25) among other cancers are closely related to inflammation. Proinflammatory stimulation factors such as IL- 6 and TNF- $\alpha$ can mediate the activation of a variety of inflammatory cells such as neutrophils and fibroblasts and inflammatory media- tors such as IL-1, IL-8, INF- $\gamma$ and NF- $\kappa$ B, which in turn cause inflammatory disorders. High levels of IL-6 and TNF- $\alpha$ have been reported in glioma patients, and these levels have been shown to be associated with the chemotherapy outcomes and the prognosis $(26,27)$.

We concluded that the occurrence of glioma is related to Wnt5a/ $\beta$-catenin signaling pathway activation, cell autophagy and inflammatory response. Our study provided a new direction for bio-targeted therapy.

\section{References}

1. Ostrom QT, Gittleman H, Fulop J, Liu M, Blanda R, Kromer C, Wolinsky Y, Kruchko C and Barnholtz-Sloan JS: CBTRUS Statistical Report: Primary brain and central nervous system tumors diagnosed in the United States in 2008-2012. Neuro Oncol 17 (Suppl 4): iv1-iv62, 2015.

2. Duchartre Y, Kim YM and Kahn M: The Wnt signaling pathway in cancer. Crit Rev Oncol Hematol 99: 141-149, 2016.

3. Chen $\mathrm{N}$ and Karantza V: Autophagy as a therapeutic target in cancer. Cancer Biol Ther 11: 157-168, 2011.

4. Kaza N, Kohli L and Roth KA: Autophagy in brain tumors: A new target for therapeutic intervention. Brain Pathol 22: 89-98, 2012.

5. Xue H, Yuan G, Guo X, Liu Q, Zhang J, Gao X, Guo X, Xu S, Li T, Shao Q, et al: A novel tumor-promoting mechanism of IL6 and the therapeutic efficacy of tocilizumab: Hypoxia-induced IL6 is a potent autophagy initiator in glioblastoma via the p-STAT3MIR155-3p-CREBRF pathway. Autophagy 12: 1129-1152, 2016.

6. Chen W, Xia T, Wang D, Huang B, Zhao P, Wang J, Qu X and Li X: Human astrocytes secrete IL-6 to promote glioma migration and invasion through upregulation of cytomembrane MMP14. Oncotarget 7: 62425-62438, 2016.

7. Kikuchi A, Yamamoto H and Kishida S: Multiplicity of the interactions of Wnt proteins and their receptors. Cell Signal 19: 659-671, 2007.

8. Lerner UH and Ohlsson C: The WNT system: Background and its role in bone. J Intern Med 277: 630-649, 2015.

9. Prakash S and Swaminathan U: $\beta$ catenin in health: A review. J Oral Maxillofac Pathol 19: 230-238, 2015.

10. Bielen $\mathrm{H}$ and Houart $\mathrm{C}$ : The Wnt cries many: Wnt regulation of neurogenesis through tissue patterning, proliferation, and asymmetric cell division. Dev Neurobiol 74: 772-780, 2014

11. Nusse R: Wnt signaling and stem cell control. Cell Res 18: 523-527, 2008.

12. Adachi K, Mirzadeh Z, Sakaguchi M, Yamashita T, Nikolcheva T, Gotoh Y, Peltz G, Gong L, Kawase T, Alvarez-Buylla A, et al: Beta-catenin signaling promotes proliferation of progenitor cells in the adult mouse subventricular zone. Stem Cells 25: 2827-2836, 2007.

13. Van Camp JK, Beckers S, Zegers D and Van Hul W: Wnt signaling and the control of human stem cell fate. Stem Cell Rev 10: 207-229, 2014.

14. Cerpa W, Godoy JA, Alfaro I, Farías GG, Metcalfe MJ, Fuentealba R, Bonansco C and Inestrosa NC: Wnt-7a modulates the synaptic vesicle cycle and synaptic transmission in hippocampal neurons. J Biol Chem 283: 5918-5927, 2008.

15. Maguschak KA and Ressler KJ: A role for $\mathrm{WNT} / \beta$-catenin signaling in the neural mechanisms of behavior. J Neuroimmune Pharmacol 7: 763-773, 2012.

16. Boitard M, Bocchi R, Egervari K, Petrenko V, Viale B, Gremaud S, Zgraggen E, Salmon P and Kiss JZ: Wnt signaling regulates multipolar-to-bipolar transition of migrating neurons in the cerebral cortex. Cell Rep 10: 1349-1361, 2015.

17. Lee SC, Kim OH, Lee SK and Kim SJ: IWR-1 inhibits epithelial-mesenchymal transition of colorectal cancer cells through suppressing Wnt/ $\beta$-catenin signaling as well as survivin expression. Oncotarget 6: 27146-27159, 2015.

18. Liu WT, Huang CY, Lu IC and Gean PW: Inhibition of glioma growth by minocycline is mediated through endoplasmic reticulum stress-induced apoptosis and autophagic cell death. Neuro Oncol 15: 1127-1141, 2013.

19. Al Dhaheri Y, Attoub S, Ramadan G, Arafat K, Bajbouj K, Karuvantevida N, AbuQamar S, Eid A and Iratni R: Carnosol induces ROS-mediated beclin1-independent autophagy and apoptosis in triple negative breast cancer. PLoS One 9: e109630, 2014. 
20. Wu S, Sun C, Tian D, Li Y, Gao X, He S and Li T: Expression and clinical significances of Beclin1, LC3 and mTOR in colorectal cancer. Int J Clin Exp Pathol 8: 3882-3891, 2015.

21. Suh Y, Afaq F, Khan N, Johnson JJ, Khusro FH and Mukhtar H: Fisetin induces autophagic cell death through suppression of mTOR signaling pathway in prostate cancer cells. Carcinogenesis 31: 1424-1433, 2010.

22. Hamed HA, Yacoub A, Park MA, Eulitt P, Sarkar D, Dimitrie IP, Chen CS, Grant S, Curiel DT, Fisher PB, et al: OSU-03012 enhances Ad.7-induced GBM cell killing via ER stress and autophagy and by decreasing expression of mitochondrial protective proteins. Cancer Biol Ther 9: 526-536, 2010.

23. Tan X, Carretero J, Chen Z, Zhang J, Wang Y, Chen J, Li X, Ye H, Tang C, Cheng X, et al: Loss of p53 attenuates the contribution of IL-6 deletion on suppressed tumor progression and extended survival in Kras-driven murine lung cancer. PLoS One 8: e80885, 2013.
24. Liu F, Zhang W, Yang F, Feng T, Zhou M, Yu Y, Yu X, Zhao W, Yi F, Tang W, et al: Interleukin-6-stimulated progranulin expression contributes to the malignancy of hepatocellular carcinoma cells by activating mTOR signaling. Sci Rep 6: 21260, 2016.

25. Banday MZ, Balkhi HM, Hamid Z, Sameer AS, Chowdri NA and Haq E: Tumor necrosis factor- $\alpha$ (TNF- $\alpha$ )-308G/A promoter polymorphism in colorectal cancer in ethnic Kashmiri population - a case control study in a detailed perspective. Meta Gene 9: 128-136, 2016.

26. Shan Y, He X, Song W, Han D, Niu J and Wang J: Role of IL-6 in the invasiveness and prognosis of glioma. Int J Clin Exp Med 8: 9114-9120, 2015

27. Zhao X, Laver T, Hong SW, Twitty GB Jr, Devos A, Devos M, Benveniste EN and Nozell SE: An NF- $\kappa$ B p65-cIAP2 link is necessary for mediating apoptotic resistance to TNF- $\alpha$ in gliomas. J Neurooncol 102: 367-381, 2011. 